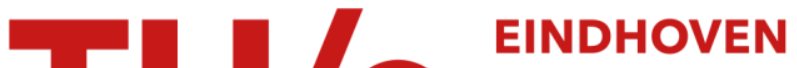

\section{All-optical buffering in all-optical packet switched cross connects}

\section{Citation for published version (APA):}

Liu, Y., Hill, M. T., Calabretta, N., Waardt, de, H., Khoe, G. D., \& Dorren, H. J. S. (2002). All-optical buffering in all-optical packet switched cross connects. IEEE Photonics Technology Letters, 14(6), 849-851.

https://doi.org/10.1109/LPT.2002.1003114

DOI:

10.1109/LPT.2002.1003114

Document status and date:

Published: 01/01/2002

\section{Document Version:}

Publisher's PDF, also known as Version of Record (includes final page, issue and volume numbers)

\section{Please check the document version of this publication:}

- A submitted manuscript is the version of the article upon submission and before peer-review. There can be important differences between the submitted version and the official published version of record. People interested in the research are advised to contact the author for the final version of the publication, or visit the $\mathrm{DOI}$ to the publisher's website.

- The final author version and the galley proof are versions of the publication after peer review.

- The final published version features the final layout of the paper including the volume, issue and page numbers.

Link to publication

\section{General rights}

Copyright and moral rights for the publications made accessible in the public portal are retained by the authors and/or other copyright owners and it is a condition of accessing publications that users recognise and abide by the legal requirements associated with these rights.

- Users may download and print one copy of any publication from the public portal for the purpose of private study or research.

- You may not further distribute the material or use it for any profit-making activity or commercial gain

- You may freely distribute the URL identifying the publication in the public portal.

If the publication is distributed under the terms of Article 25fa of the Dutch Copyright Act, indicated by the "Taverne" license above, please follow below link for the End User Agreement:

www.tue.nl/taverne

Take down policy

If you believe that this document breaches copyright please contact us at:

openaccess@tue.nl

providing details and we will investigate your claim. 


\title{
All-Optical Buffering in All-Optical Packet Switched Cross Connects
}

\author{
Y. Liu, Member, IEEE, M. T. Hill, N. Calabretta, H. de Waardt, G. D. Khoe, Member, IEEE, and H. J. S. Dorren
}

\begin{abstract}
In this letter, we show that optical packets can be routed in an optical fiber by using an optical threshold function that controls a wavelength converter switch. The optical threshold function is made from two coupled lasers. Experimental evidence is given.
\end{abstract}

Index Terms-Buffer memories, optical fiber communication, optical fiber delay lines, packet switching.

\section{INTRODUCTION}

A LL-OPTICAL packet switched networks, in which routing and switching are performed in the optical domain, are seriously considered as a possible long-term route in the evolution of the present telecommunication networks. A severe complication is the contention that takes place when two or more optical packets arrive simultaneously at the same packet switch. Optical buffering has to be used to handle this problem [1]-[3].

We consider all optically packet switched cross connects that have a generic node structure as presented in Fig. 1 (see [3]). The wavelength-division-multiplexing (WDM) channels are initially demultiplexed. In the switching fabric, three important steps take place, synchronization of the packets, buffering of the packets and switching of the packets. Afterwards, the packets are multiplexed and fed into the optical transmission line.

In [3], routing of optical packets in a packet switched cross connect was demonstrated by using electronically controlled wavelength routing switches $(1 \times N$ switches $)$. All-optical packet switching can potentially lead to routing of optical data packets at ultrahigh speed. An example of a $1 \times 2$ all-optical packet switch in which the processing of the header information is carried out in optics is presented in [4]. In order to fully employ the advantages of all-optical packet switching, methods for all-optical buffering have to be developed.

In this letter, we present an all-optical buffering concept. Similarly, as in [3], optical buffering is realized by using a combination of optical delay lines and wavelength routing switches. We demonstrate experimentally how all-optical techniques can be employed for optical buffering purposes. In particular, we show that an optical packet can be routed in an optical fiber buffer by using a wavelength converter that is controlled by an optical threshold function (OTF). Our results suggest that it is

Manuscript received August 24, 2001; revised February 4, 2002. This work was supported by the Netherlands Organization for Scientific Research (NWO) under the "NRC photonics" Grant.

The authors are with COBRA Research Institute, Eindhoven University of Technology, 5600 MB Eindhoven, The Netherlands (e-mail: Y.Liu@tue.nl).

Publisher Item Identifier S 1041-1135(02)03394-3.

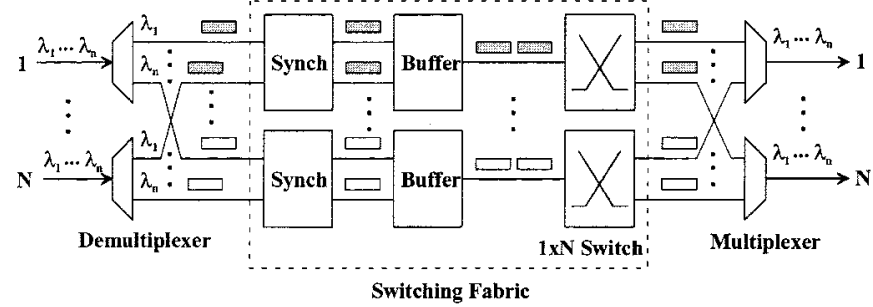

Fig. 1. Generic node structure for all optically packet switched cross connects.

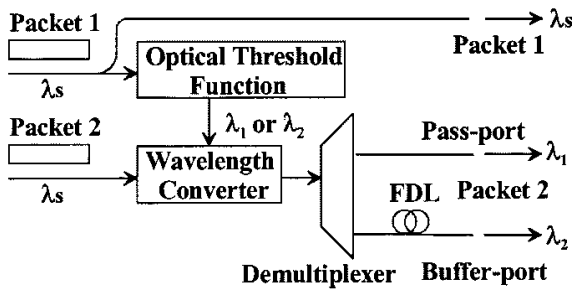

Fig. 2. System concept for all-optical buffering. FDL: Fiber delay line.

not necessary to recognize and process optical packet headers for buffering purposes.

\section{SYSTEM CONCEPT}

Since wavelength routing switches can only handle one packet at the same time, in cases of packet contention one of the packets has to be buffered into a fiber delay line. An all-optical concept suitable for these purposes is presented schematically in Fig. 2. We assume that packets arrive in a synchronized way and that Packet 1 has a higher priority than Packet 2 . The optical power of Packet 1 is firstly split into two parts: the first part passes the node directly and is not delayed. Another part is injected into an OTF [5] that acts as an optical arbiter to decide if packet contention takes place. If packet contention takes place, Packet 2 is delayed. By resetting the wavelength and combining the signals, Packet 2 leaves the optical fiber buffer after Packet 1 (not displayed in Fig. 2).

The OTF that we use is based on two coupled ring lasers. The device is depicted in Fig. 3. The semiconductor optical amplifiers (SOAs) act as the gain mediums and the Fabry-Pérot filters act as wavelength selective elements. In [5], it is shown that a system of two coupled lasers can have two possible states. In State 1, light from Laser 1 suppresses lasing in Laser 2. Conversely, in State 2, light from Laser 2 suppresses lasing in Laser 1 . The SOA currents are biased asymmetrically so that the system is in State 1 if no external light is injected. To change states, lasing in the dominant laser is stopped by injecting light, 


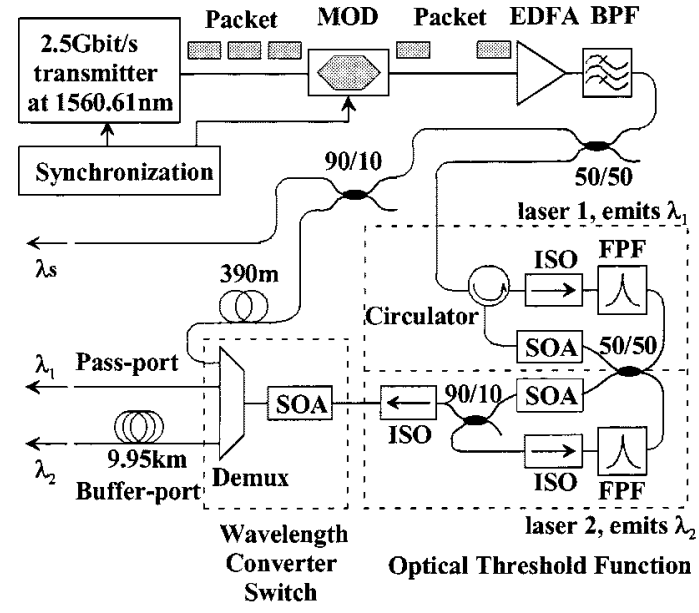

Fig. 3. Experimental setup. MOD: External optical modulator. EDFA: Erbium-doped fiber amplifier. BPF: Optical bandpass filter. SOA: Semiconductor optical amplifier. ISO: Optical isolator. FPF: Fabry-Pérot filter, and Demux: optical demultiplexer.

not at the dominant laser's lasing wavelength, into the dominant laser [5]. Hence, Laser 2 becomes the dominant laser (State 2). However, the asymmetrically biased SOA currents ensure that the system returns to State 1 if injection of external light is stopped. The operation of the OTF is similar to an optical flip-flop memory that is described in detail in [5]. For specific injection currents and amount of coupling between the lasers the system can form a threshold function rather than a flip-flop memory.

The output light of the OTF is used to control a wavelength converter that converts the wavelength of Packet 2. A demultiplexer is used to route Packet 2 into a passport or a bufferport, depending on the converted wavelength of Packet 2. The optical buffer that is described in Fig. 2 could have three different nontrivial input cases that are described as follows:

Case 1) Packet 1 and Packet 2 are present and a potential collision takes place. Due to the presence of Packet 1 , the OTF is forced into State 2 and emits continuous-wave light (CW-light) at wavelength $\lambda_{2}$. Hence, the wavelength of Packet 2 is converted to $\lambda_{2}$ and routed into the fiber buffer. Packet 1 can pass the node directly.

Case 2) Packet 1 is present while Packet 2 is absent (no contention). Packet 1 can pass the node directly. Part of the power of Packet 1 is fed into the OTF forcing the OTF into its State 2, emitting CW-light at wavelength $\lambda_{2}$.

Case 3) Packet 1 is absent while Packet 2 is present (no contention). The OTF outputs CW-light at wavelength $\lambda_{1}$ due to the absence of Packet 1. Thus the Packet 2 is directed into the passport after wavelength conversion.

In [3], it is shown that the wavelength of the Packet 2 can be reset by using interferometric wavelength converters. Also network architectures in which this optical buffering concept can be applied is given in [3].

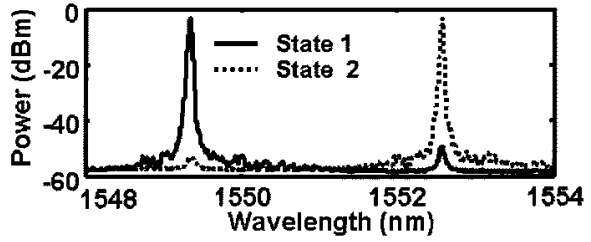

Fig. 4. Spectral output of two states of the OTF. The solid curve (-) represents State 1 (Laser 1 dominant), and the dotted curve (.) represents State 2 (Laser 2 dominant).

\section{EXPERIMENT AND RESULTS}

The experimental setup for demonstration of all-optical buffering by using an OTF that control a wavelength routing switch is presented schematically in Fig. 3.

An external modulator is used to generate optical packets. The bit rate is $2.5 \mathrm{~Gb} / \mathrm{s}$, and the wavelength is $1560.61 \mathrm{~nm}$. The bit patterns in the packets have a data format of $2^{15}-1$ nonreturn-to-zero pseudorandom binary sequence. The packets are then amplified by an EDFA and subsequently filtered by a tunable bandpass filter with 3-nm bandwidth. An optical splitter is used to direct half of the optical power of the packet into the OTF via an optical circulator, representing Packet 1 that is coupled into OTF (see Fig. 2). The other half of the optical power is coupled into a 90/10 coupler.

The 90/10 coupler splits the optical power of the packet into two parts: one part goes directly to the output, representing Packet 1 that passes the node directly (see Fig. 2). Another part, representing Packet 2 (see Fig. 2), is firstly delayed by $1.95 \mu$ s (390-m fiber) corresponding to the time that is needed to let the OTF change states, and then fed into the wavelength converter. The wavelength of the packet is converted via cross-gain modulation (XGM). The demultiplexer spatially directs the packet into a different port based on the wavelength of the packet. In the buffer port, $9.95-\mathrm{km}$ fiber is employed for buffering purposes. This corresponds to a delay of $49.75 \mu$ s for the packet.

In the first experiment, we demonstrate the operation principle of the OTF. As shown in Fig. 3, the OTF is implemented by using two coupled ring lasers. The injected currents to the SOAs in the OTF are $177 \mathrm{~mA}$ (the threshold current is $82 \mathrm{~mA}$ ) for Laser 1 and $192 \mathrm{~mA}$ for Laser 2 (the threshold current is $117 \mathrm{~mA}$ ), respectively. The wavelength of each laser is $\lambda_{1}=$ $1549.32 \mathrm{~nm}$ and $\lambda_{2}=1552.52 \mathrm{~nm}$. The spectrum of the OTF is presented in Fig. 4. It can be observed from Fig. 4 that contrast ratio between the two states in the OTF is over $45 \mathrm{~dB}$. In Fig. 5, the switching characteristics of the OTF is presented. The upper panel of Fig. 5 shows the optical packet. The dynamic behavior of the OTF is presented in the middle and lower panel of Fig. 5. It can be observed from Fig. 5 that the state (the output wavelength) of the OTF changes if an optical packet is injected. As soon as injection of the packet is stopped the OTF switches back to its original state.

In the second experiment, we demonstrate that an OTF in combination with a wavelength routing switch can be used for buffering purposes. An optical packet, representing Packet 1 (see Fig. 2), is injected into the OTF and changes the state of OTF into State 2 (Laser 2 dominant). Thus, the dominant wavelength of the OTF is $\lambda_{2}$. Meanwhile, another packet, representing Packet 2 (see Fig. 2) is coupled into the wavelength converter and its wavelength is converted to $\lambda_{2}$ via XGM. The 


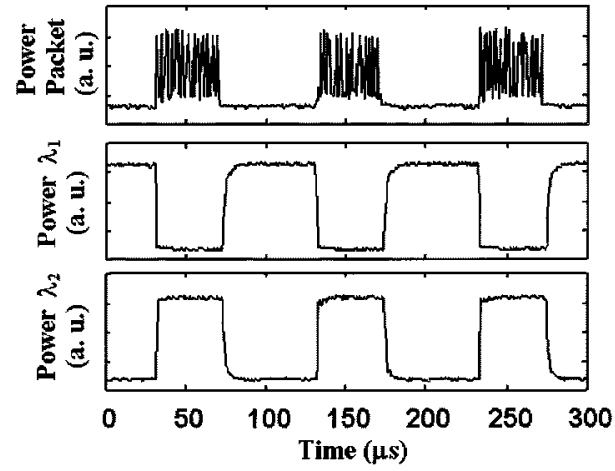

Fig. 5. Dynamic output of the OTF with and without the presence of packet input. The upper panel is the traces of the external optical packet. The middle and lower panel are the dynamic output of OTF at each wavelength.

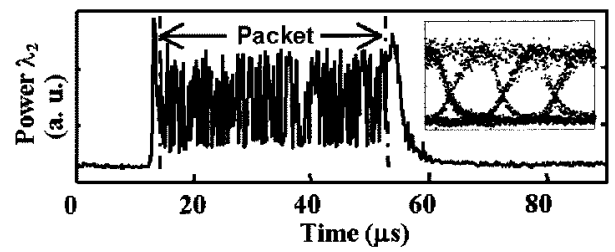

Fig. 6. Oscilloscope trace after wavelength conversion showing that the whole packet is converted to wavelength $\lambda_{2}$ within the duration of wavelength $\lambda_{2}$.

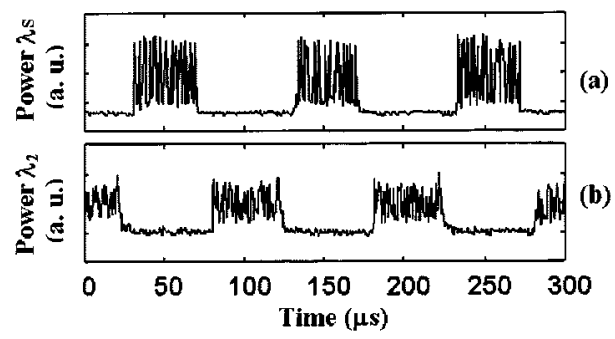

Fig. 7. Oscilloscope traces for $2.5-\mathrm{Gb} / \mathrm{s}$ packets showing the all-optical buffer is realized. (a) The packets pass the node directly with the wavelength $\lambda_{s}$. (b) The packets experience $49.75-\mu$ s delay caused by the fiber delay line.

SOA for wavelength conversion is biased to $350 \mathrm{~mA}$. The result is shown in Fig. 6, which indicates that the packet is converted into wavelength $\lambda_{2}$ for the time that the OTF is in State 2. The optical power of the packet is relatively small due to gain saturation in the wavelength conversion. The eye pattern of converted pulses in the packet after the wavelength conversion is also presented in Fig. 6. The wide open eye without spikes indicates that error-free propagation through the wavelength converter is possible. In Fig. 7, the result of the all-optical buffering is presented. Fig. 7(a) shows the oscilloscope traces of the packets that pass the node directly with the wavelength $\lambda_{s}$. These packets represent Packet 1 (see Fig. 2). Fig. 7(b) shows the oscilloscope traces of the packets that are directed into the buffer port and experience $49.75-\mu$ s delay caused by a $9.95-\mathrm{km}$ fiber delay line. These packets represent Packet 2 (see Fig. 2). Fig. 7 clearly shows that the all-optical buffering functions correctly when two packets contend for the output port.

\section{DISCUSSION}

We have presented a new method for all-optical buffering. It has been demonstrated experimentally that an optical packet can be routed all optically into an optical fiber buffer in case of potential contention between two optical packets. This method is advantageous since we need no complicated header recognition techniques to route an optical packet into a buffer.

Crucial in our method is the OTF that controls a wavelength converter switch. Experimental results indicate that a contrast ratio of more than $45 \mathrm{~dB}$ between the output states in OTF can be obtained. Moreover, a clear open eye diagram through the wavelength converter can be achieved.

In our experiment, the wavelength conversion utilizes XGM in a single SOA, leading to a strong degradation of the extinction ratio (ER). However, a better ER can be achieved by using an interferometric wavelength converter based on cross-phase modulation.

The duration of the packet is related to the particular implementation of the OTF used in the experiment. The lasers that are used to form the OTF were constructed from standard commercially available fiber pigtailed components having cavity lengths of many meters. Thus the component lasers had low intrinsic modulation bandwidths, which imply that several microseconds are required to change the states of the OTF. However, integrated versions of the OTF having cavity length of several millimeters could attain speeds in the gigahertz range.

Finally, the concept of the OTF can be extended to a multilevel state OTF, so that contentions between a large number of packets can be handled.

\section{ACKNOWLEDGMENT}

The authors would like to thank F. M. Huijskens for technical assistance and E. Tangdiongga for helpful discussions.

\section{REFERENCES}

[1] D. K. Hunter, M. C. Chia, and I. Andonovic, "Buffering in optical packet switches," J. Lightwave Technol., vol. 16, pp. 2081-2094, Dec. 1998.

[2] Y. Liu, M. T. Hill, H. de Waardt, and H. J. S. Dorren, "All-optical switching of packets for all-optical buffering purposes," in Proc. ECOC'2001, Amsterdam, The Netherlands, Paper Wed. B. 2.4, pp. $310-311$.

[3] C. Guillemot, M. Renaud, P. Gambini, C. Janz, I. Andonovic, R. Bauknecht, B. Bostica, M. Burzio, F. Callegati, and M. Casoni et al., "Transparent optical packet switching: The European ACTS KEOPS project approach,” J. Lightwave Technol., vol. 16, pp. 2117-2134, Dec. 1998.

[4] M. T. Hill, A. Srivatsa, N. Calabretta, Y. Liu, H. de Waardt, G. D. Khoe, and H. J. S. Dorren, " $1 \times 2$ optical packet switch using all-optical header processing,” Electron. Lett., vol. 37, pp. 774-775, June 2001.

[5] M. T. Hill, H. de Waardt, G. D. Khoe, and H. J. S. Dorren, "All-optical flip-flop based on coupled laser diodes," J. Quantum Electron., vol. 37, pp. 405-413, Mar. 2001. 